This section of the Final Report is also paper number HT-FED2004-56577,
Proceedings of HT-FED2004, Summer HT/FED Joint Conference, July 11-15, 2004,
Charlotte, NC.

\title{
THE EFFECT OF MARTIAN DUST ON RADIATOR PERFORMANCE
}

\author{
D. Keith Hollingsworth Larry C. Witte Jaime Hinke \\ Department of Mechanical Engineering \\ University of Houston \\ Houston, Texas 77204-4006 \\ Kathryn Hurlbert \\ NASA Johnson Space Center
}

\begin{abstract}
Experiments were performed in which the effective emittance of three types of radiator coatings was measured as Martian dust simulant was added to the radiator surface. The apparatus consisted of multiple radiator coupons on which Carbondale Red Clay dust was deposited. The coupons were powered by electric heaters, using a guard-heating configuration to achieve the accuracy required for acceptable emittance calculations. The apparatus was contained in a vacuum chamber that featured a liquid-nitrogen cooled shroud that simulated the Martian sky temperature. Radiator temperatures ranged from 250 to $350 \mathrm{~K}$ with sky temperatures from 185 to $248 \mathrm{~K}$.

Results show that as dust was added to the radiator surfaces, the effective emittance of the high-emittance coatings decreased from near 0.9 to a value of about 0.5 . A low-emittance control surface, polished aluminum, demonstrated a rise in effective emittance for thin dust layers, and then a decline as the dust layer thickened. This behavior is attributed to the conductive resistance caused by the dust layer.
\end{abstract}

\section{INTRODUCTION}

Radiators have been identified as an enabling technology for the human exploration and development of space. They are standard components of the heat rejection subsystem of space vehicles, and are used to reject waste heat to space and/or a planetary environment. They are typically large components of a thermal control system for a space vehicle, and in some cases safety factors are used to oversize them when the operating environment cannot be fully characterized. Over-sizing can impose significant weight and size penalties that might be prohibitive for future missions.
Radiators will be a critical element in the thermal control system for future robotic and human exploration missions to Mars. Radiator performance depends on the radiating surface area, the emittance and absorptance of the radiator surface, the operational temperature of the radiator, the effective sky temperature of the surroundings of the radiator, solar radiation and atmospheric irradiation levels, convection to or from the Martian atmosphere, and other conditions that could affect the nature of tine radiator suriace, such as dust accumuiation or oxidation.

Dust is expected to be a major contributor to the local environmental conditions at the Mars surface. There is evidence that indeed dust will be accumulated on radiating surfaces on the Martian surface, as described by Landis [1]. Landis and co-workers have investigated several aspects of dust accumulation on radiating surfaces $[2,3]$. He described the results of dust accumulation measurements on the Mars Sojourner Rover solar array during the Pathfinder mission. Landis' work served as an important stimulus for the studies described herein.

Our work is also informed by the design work of Johnson and Brinza [4] for what was called MTERC (Mars Thermal Environment and Radiator Characterization Experiment. They proposed flying an apparatus on a rover to Mars to gather information about how radiator performance is affected by radiator size, radiator temperature, the effective sky temperature, and local conditions on the Martian surface. The apparatus used a comparison between clean and dusted radiators, just as we have used in our studies. It was also designed to allow a measurement of the Martian sky temperature which is still unknown. 
This paper reports a study of the effect of Martian dust accumulation on radiator performance. It is comprised of quantitative measurements of emittance for a range of dust accumulation levels on surfaces of known emittance under clean conditions. Results were obtained under vacuum conditions sufficient to reduce convection effects virtually to zero.

\section{EXPERIMENTAL METHODOLOGY}

The experimental program required design and fabrication of radiator test "coupons" covered by a variety of candidate coatings being used or considered for use by NASA for thermal radiators that operate near $300{ }^{\circ} \mathrm{K}$. The emittance measurements follow the calorimetric technique: the coupons are designed to be nearly adiabatic at all surfaces other than the radiator test surface and an energy balance is applied to yield the radiative component of the heat transfer, and thus the effective emittance of the test surface. Eight of these coupons were operated simultaneously at each experimental condition so that a direct comparison of the effective emittance, $\varepsilon$, could be made between the coatings for the same amount of dust. These coupons will be described in the next section. The term 'effective emittance' refers to the value of the emittance as measured using the calorimetric method described in the sections that follow. That method averages over local variations in emittance on the coupon surface and over the wavelength spectrum present in the radiation exchanged between the (dust-covered) test surface and the chamber shroud. The technique also absorbs any conductive loss or radiative transfer between the surface coating and the dust layer into the effective $\varepsilon$.

The candidate radiator coatings to be tested were Z93P white silicate paint $(\varepsilon=0.93)$, NS43G conductive off-white silicate paint $(s=0.91)$, and 10 mil silver Teflon film $(c=0.86)$. The coatings were applied to the coupon tops by the staff of the Thermal Branch of the NASA Goddard Space Flight Center. The emittance values shown in parentheses above were measured at NASA Goddard directly from the coatings applied to the test surfaces. The same coatings were applied to two coupons to provide redundancy between coupons. The test surfaces on two of the eight coupons were uncoated polished aluminum ( $\varepsilon=0.039$ as measured using an emissometer at the NASA Johnson Space Center). One of the aluminum surfaces was subjected to the same level of dusting as the other six coated coupons. The other uncoated aluminum coupon was kept clean throughout all the testing to serve as a known lowradiation baseline with which the non-radiative losses to the air could be measured. Although the test chamber was operated at a gas density low enough to stop density-driven motions (convection), conduction through the still air remained a major source of heat flow. The undusted low- $\varepsilon$ coupon provided a measure of that heat flow for each experimental condition.

The dust used in these experiments is Carbondale Red Clay (CRC), one of NASA's standard simulants of Mars dust. The comparison of its constituents with a Martian soil sample obtained by the Viking probe is shown in Table 1 . The temperature matrix representing the range of radiator coupon surface temperatures and so-called "sky" temperatures was also selected to conform to Martian data from probes. Table II shows the test matrix with the marks showing the combinations of $T_{\mathrm{rad}}$ and $T_{\text {sky }}$ selected for these experiments.

\begin{tabular}{|c|c|c|}
\hline & $\begin{array}{c}\text { Mars Soil } \\
\text { (Viking) }\end{array}$ & $\begin{array}{c}\text { Carbondale } \\
\text { Red Clay }\end{array}$ \\
\hline $\mathrm{SiO}_{2}$ & $43.5 \%$ & $56.0 \%$ \\
\hline $\mathrm{TiO}_{2}$ & 0.6 & 1.0 \\
\hline $\mathrm{A}_{2} \mathrm{O}_{3}$ & 7.3 & 19.2 \\
\hline $\mathrm{Fe}_{2} \mathrm{O}_{3}$ & 17.5 & 12.0 \\
\hline $\mathrm{MgO}$ & 6.0 & 0.6 \\
\hline $\mathrm{CaO}$ & 5.7 & 0.6 \\
\hline $\mathrm{K}_{2} \mathrm{O}$ & 0.5 & 0.5 \\
\hline $\mathrm{SO}_{3}$ & 6.7 & - \\
\hline
\end{tabular}

Table I: Comparison of Mars dust simulant with Martian soil sample.

\begin{tabular}{|c|c|c|c|}
\multicolumn{1}{c|}{$T_{\text {ret }}(K)$} & 185 & 223 & 248 \\
\hline 250 & $\bullet$ & & \\
\hline 300 & $\bullet$ & $\bullet$ & $\bullet$ \\
\hline 350 & $\bullet$ & $\bullet$ & $\bullet$ \\
\hline
\end{tabular}

Tahle !l: Test matrix.

\section{EXPERIMENTAL APPARATUS AND PROCEDURE}

Vacuum Chamber. Experiments were performed in the Thermal Test Facility of the Energy Systems Division at NASA-JSC. Figure 1 shows the bell vacuum chamber used to produce the vacuum levels needed to eliminate convection. It was capable of pressures down to $10^{-7}$ torr. The chamber had an interior height of approximately $91 \mathrm{~cm}$ when placed on the base shown in the foreground of the picture. For these experiments, an elevated aluminum platform was placed $45 \mathrm{~cm}$ above the chamber base and served as the support for the coupons. The chamber wall above the platform was fitted with a shroud cooled by liquid nitrogen so that the coupons see a "sky" temperature uniform to $\pm 2{ }^{\circ} \mathrm{K}$.

Figure 2 shows how the coupons were situated on the elevated platform. Coupons with the same coatings were diametrically opposed as shown. Microscope slides were situated between the coupons. These slides were used to determine the mass of dust provided for different degrees of dusting. The procedure was as follows: After each dusting, two diametrically-opposed slides were retrieved, weighed, and the amount of dust added calculated by subtracting the weight of a clean slide. After testing was completed for a given level of dusting, the vacuum 
chamber was opened, more dust was applied, and two more slides were retrieved. These slides then represented the weight of two dustings for all the coupons. This was repeated until testing for four levels of dusting was completed. Eight slides limited the number of dusting levels to four.

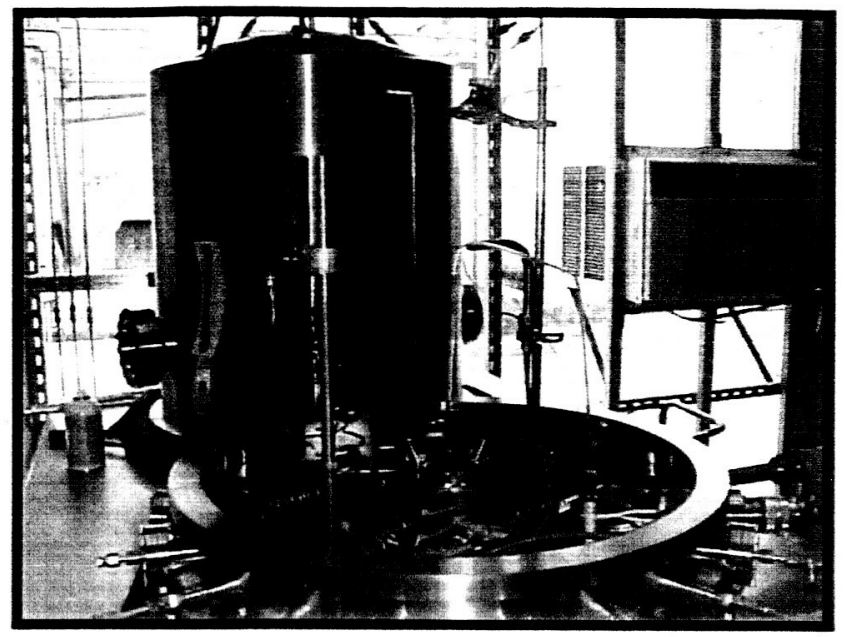

Figure 1. Photograph of vacuum system used to control air pressure and sky temperature.

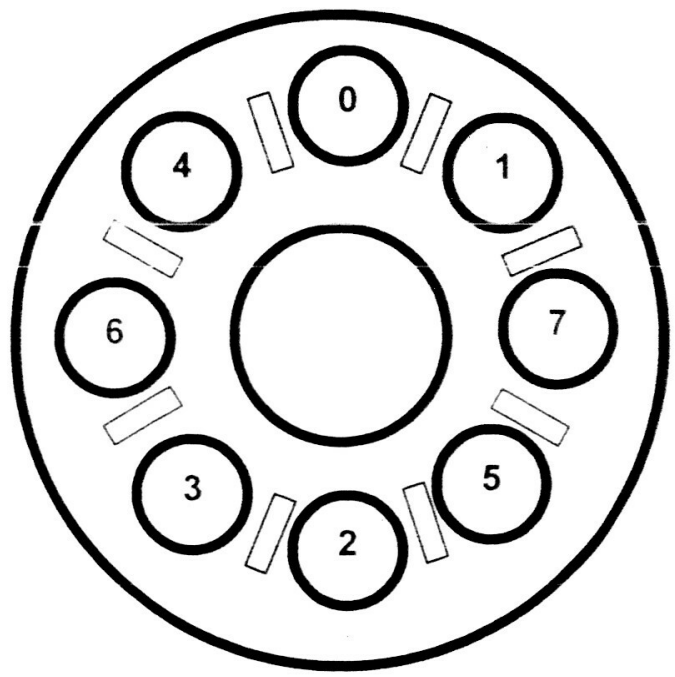

Figure 2. Top view of test platform showing layout of radiator coupons:

1 \& 3: Z-93P white silicate paint

4 \& 5: NS-43G white silicate paint

6 \& 7: 10 mil silver Teflon film

0 \& 2: polished aluminum.

Dust application apparatus. Because multiple coupons were used in the experimental set-up, a device that applied the same amount of dust uniformly to every coupon had to be developed. A schematic of this system is shown in Figure 3. Dust is placed in a central reservoir (indicated by the orange container) and is aerated by an impeller at the bottom of that container. The impeller creates an air/dust suspension which rises slowly in tube surrounding the reservoir. The suspension spreads radially at the chamber top as indicated by the red arrows, and settles on the coupons (yellow) below. If needed, the dust column can be given a "boost" by intermittently activating a small fan located below the dust reservoir (light blue). Visual inspection of samples showed that dust is distributed with acceptable uniformity on each coupon and that a single dusting deposits a nearly equal amount of dust on all eight coupons. Preliminary testing showed that the deposited dust weight varied almost linearly with the activation time for the impeller given the same initial dust volume in the reservoir.

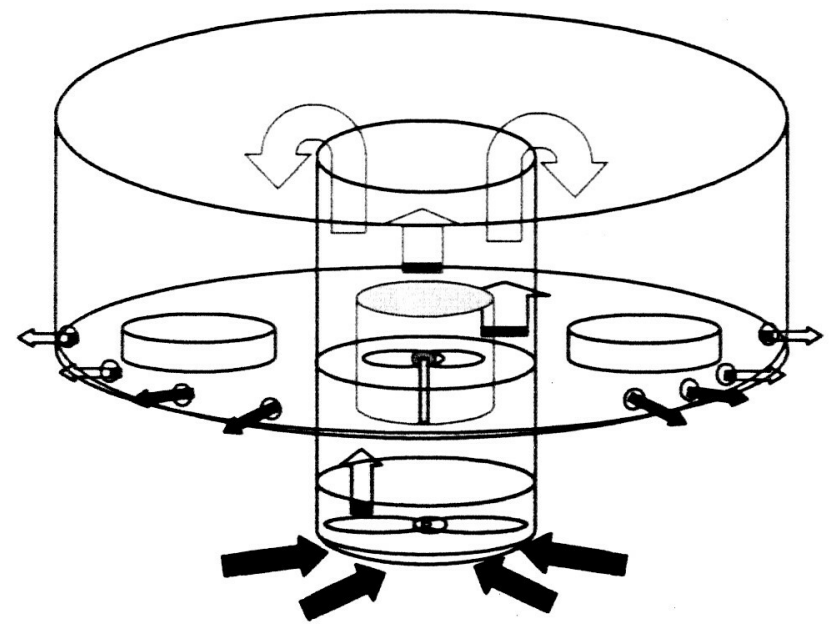

Figure 3. A schematic depiction of the dusting apparatus.

The undusted coupons are shown arrayed on the platform in Figure 4. The large hole at the center admits the central column of the dusting apparatus. Once dusting was completed, the dusting apparatus was removed before the vacuum chamber was closed and the vacuum created for the tests. Figure 5 shows the coupons after the fourth dusting where the dust weight per surface area was $5.9 \mathrm{mg} / \mathrm{cm}^{2}$. Note the areas where the pair of microscope slides were removed.

Radiator Coupons. The coupons used guard heating to direct a known heat flux through the radiator test surface. The final design of the coupons is shown in Figure 6. The coupons have a central cylindrical section which is $7.62 \mathrm{~cm}$ ( 3 inches) in diameter. Power is supplied by two Minco Inc. Thermofoil heater/sensors, each with a single integral resistance temperature device (RTD). The upper section of the coupon is a $3.2 \mathrm{~mm}$ ( $1 / 8 \mathrm{inch})$ aluminum disk. The test coating covers the upper surface of this disk. Attached to the lower surface of the disk is the main heater/RTD. Below the main heater is a 12.7 $\mathrm{mm}(1 / 2$ inch) thick Teflon disk which serves as a highresistance element between the main and guard heaters. The guard heater/RTD is attached between the Teflon and a cupshaped aluminum base that serves as a heat spreader. The sides 
of this base extend to the full height of the coupon and are separated from the central stack by a radial gap of approximately $3.2 \mathrm{~mm}(1 / 8 \mathrm{inch})$. The gap is undercut at its base to allow dust to accumulate without forming an unwanted conductive path across the gap. Given that the chamber is operated at vacuum, the gap forms a high thermal resistance between the central stack and the aluminum guard. The aluminum base is supported on three stainless steel pins that fit into indentions drilled in to the test platform. This arrangement reduces heat flow from the guard heater to the platform and allows the coupons to be positioned on the platform with a high degree of repeatability. Adjacent elements of the coupon are attached with pressure-sensitive adhesive sheets from $3 \mathrm{M}$ Inc.

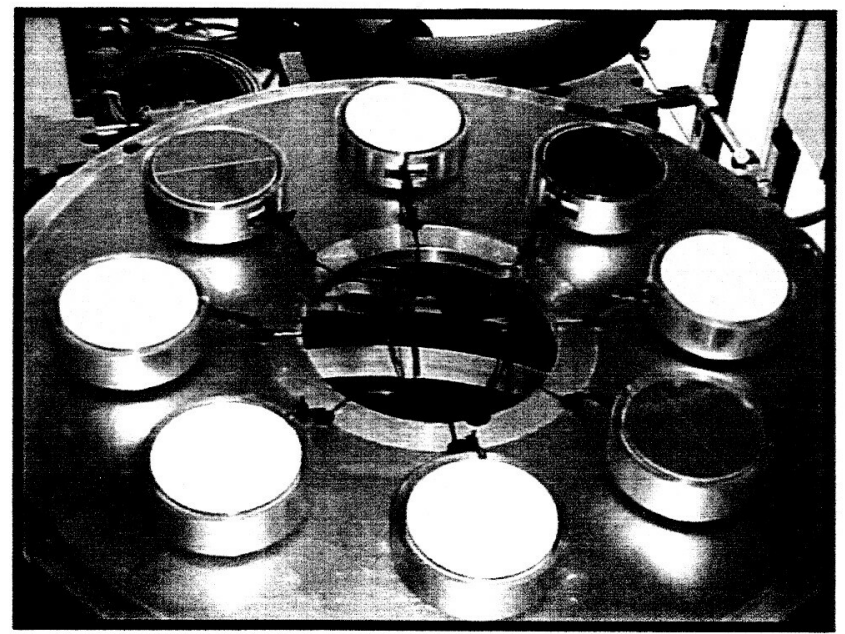

Figure 4. Undusted coupons positioned on the elevated platform.

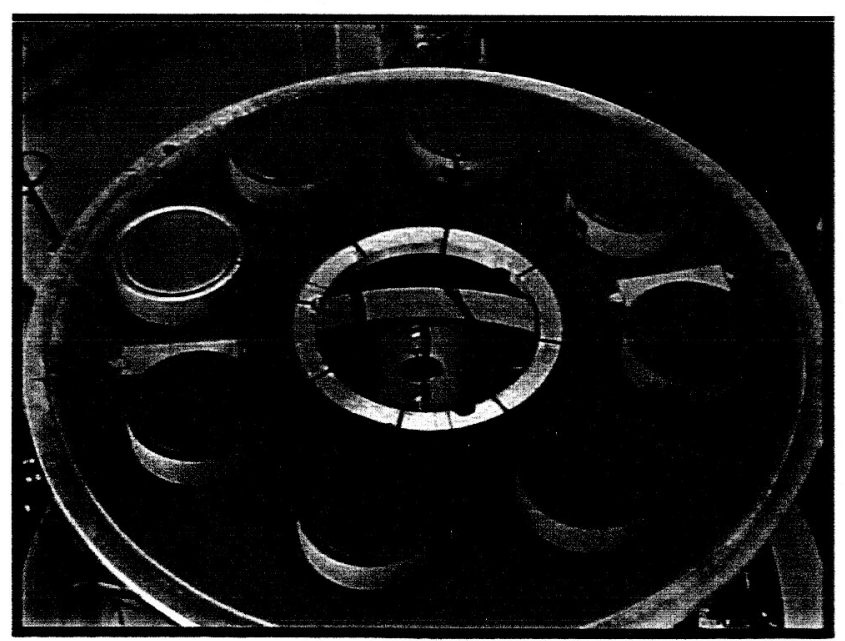

Figure 5. Coupons after final dusting. Dust weight per radiator area $=5.9 \mathrm{mg} / \mathrm{cm}^{2}$.

A power supply routes separately controlled DC currents to the two heaters. Power is adjusted until both the main and the guard RTDs read the target radiator temperature for the experiment. The high conductivity of the aluminum base assures that the bottom and sides of the Teflon disk and of the circumference of the test surface are facing isothermal surfaces held at the temperature of the main heater. The heat flux from the main heater follows the only remaining temperature gradient: upward through the test surface.

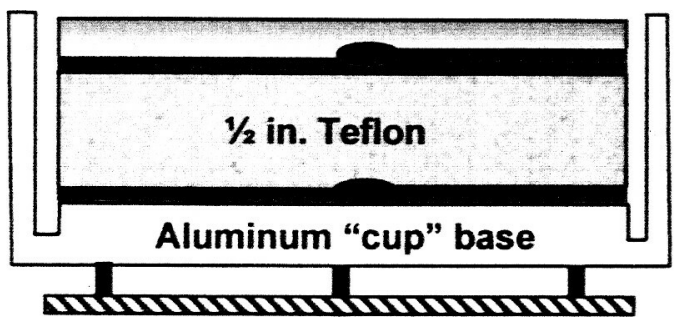

Figure 6. A cutaway schematic view of the final design of the radiator coupons. Heaters are shown in red, RTDs in blue.

The design of the first generation of coupons did not include the aluminum base or the stainless standards. Instead, a second Teflon disk was placed below the guard heater and the sides of the coupon were covered by low-emissivity aluminum tape to minimize heat radiated from the sides. However, a FLUENT computer simulation of this design under typical experimental conditions shows that the conductive loss through the air from the sides of the coupon was too large. Figure $7(a)$ shows the results of the FLUENT simulation at 0.1 torr for the firstgeneration (Mod 1) design. (FLUENT assumes the conductivity of air at that pressure is equal to the value obtained at one atmosphere, a reasonable assumption for an enclosure of this size.)

Figure 7 (b) illustrates how the cup-shaped aluminum base moves the high-gradient area away from the side of the central stack and produces a more isothermal structure. Also, the leg supports break the conduction path to the support platform. In the Modl design, the simulation finds that of the main heater power, $64 \%$ goes to radiative transfer, $14 \%$ goes to conductive transfer from the test surface to the air, and $22 \%$ goes to heat loss through the remaining surfaces. The results for the Mod 2 design are $83 \%$ radiative transfer, $14 \%$ conduction, and $3 \%$ other losses. The conduction loss through the air is inherent in the design and is measured with the polished, undusted coupon as described in the Methodology Section. An additional benefit of the Mod 2 design is that it achieves equilibrium for a desired experimental condition in a much shorter time because of the replacement of the lower Teflon disk with the high-diffusivity aluminum base.

Data Acquisition and Control System. A custom-designed data acquisition and control system was used to gather temperature and power data while controlling the energy provided to the main and guard heaters. Sixteen precision DC power supplies provided manually-controlled current to the heaters. 

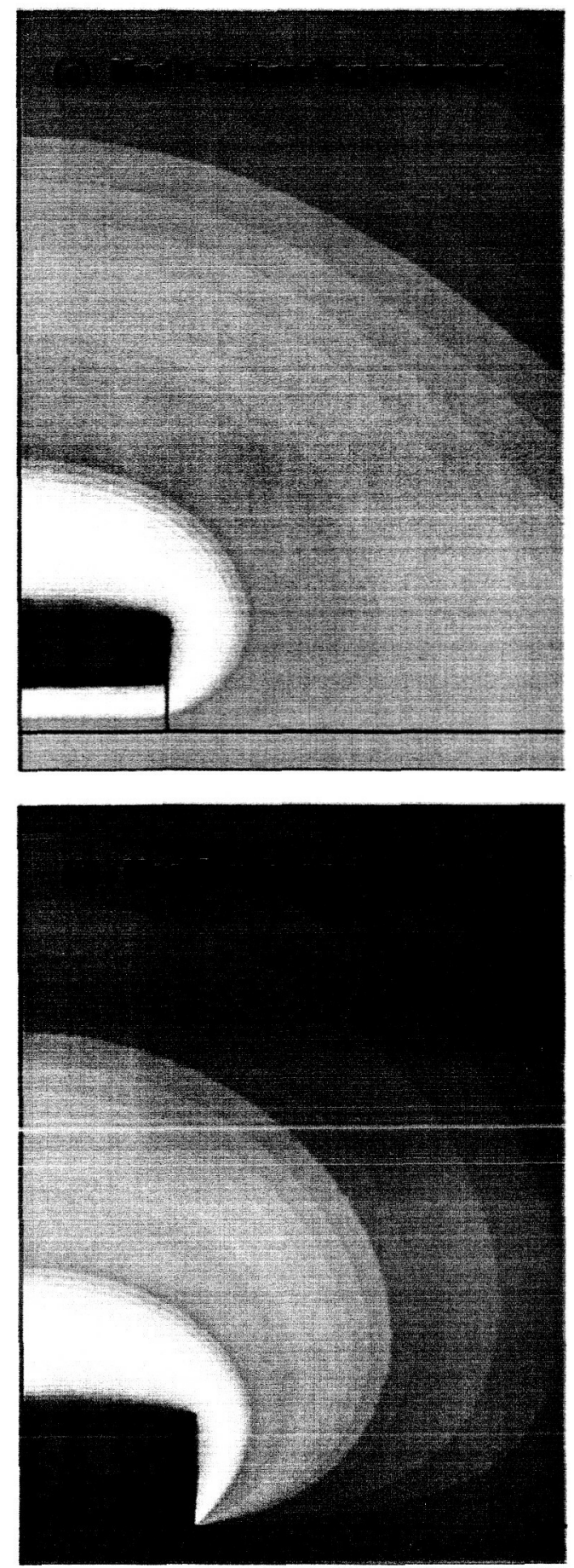

Figure 7. Predicted temperature contours for (a) the original design, Mod 1, and (b), the modified design, Mod 2, for the radiator coupons.

The RTDs were read by an IoTech Inc. Daqbook data acquisition system controlled by a laptop computer. The unit included two purpose-built RTD acquisition/conversion cards which were operated in three-wire mode to remove the lead resistance from the computation of the temperature. The complete RTD acquisition system was calibrated in a controlled-temperature environment prior to use in the vacuum chamber. The IoTech system also acquired the voltage across each of the 16 heater circuits along with the voltage drop in one lead of each of the heaters. These measurements and the resistance of each heater were used to compute the heat generated in each heater. All the output data were recorded on a laptop for remote analysis. A separate system operated by NASA JSC staff controlled and monitored the shroud temperature in the vacuum chamber. That system used ten thermocouples placed around the chamber wall and was manually controlled to produce a spatial variation of no more than $\pm 2 \mathrm{~K}$.

Experimental Procedure. Data for five dust levels (counting the no-dust baseline) were measured. For each level, the temperature matrix in Table 2 was executed. With the dust level established, the chamber was sealed and purged with nitrogen to remove any water vapor from the system. The chamber was then pumped down to $10^{-5}$ torr or below. A shroud temperature, $T_{s h y}$, from the experiment matrix was stabilized by the liquid nitrogen system. The heater voltages were then manually adjusted to yield the desired main RTD temperature, $T_{\text {surface }}$, along with a temperature difference between the main and guard RTDs, $\Delta T$, of typically less that $0.25 \mathrm{~K}$ for each coupon. In most cases the procedure required several hours to accomplish for each $\left(T_{\text {sag }}, T_{\text {surface }}\right)$ pair.

An energy balance on the aluminum test surface and the main heater includes heat losses into the Teflon disk, conduction to the air from the test surface, and radiation from the test coating:

$$
\dot{W}_{\text {electric }}=\dot{Q}_{\text {Teffon }}+\dot{Q}_{\text {air }}+\dot{Q}_{\text {Rad }} \text {. }
$$

Equation (1) expressed in terms of the measurands of the system and solved for surface radiation yields

$$
\begin{gathered}
\left.\left.\dot{Q}_{\text {Rad }}=\frac{C_{\text {cal }}\left(V_{\text {meas }}-V_{\text {leads }}\right)^{2}}{R}\right)_{\text {heater }}-\frac{\Delta T}{L / k A}\right)_{\text {Tefion }} . \\
-\left(S k_{\text {air }}\right)_{\text {Coupon } 0}\left(T_{\text {rad }}-T_{\text {sky }}\right)
\end{gathered}
$$

The effective emittance, $\varepsilon$, was then calculated using the largeisothermal-enclosure model,

$$
\varepsilon=\dot{Q}_{\text {rad }} / \sigma A\left(T_{\text {rad }}^{4}-T_{s k y}^{4}\right) .
$$

The energy provided to the heater is given by the first term on the right in Eq. 2. The voltage to the main heater circuit is $V_{\text {meas }}$, and $V_{\text {leads }}$ is twice the measured voltage drop in one side of the leads to that heater. The heater resistance, $R$, was measured for the operating temperature range of the heater. The second term in Eq. 2 is a one-dimensional model of the residual heat flow across the Teflon disk where $L, K$ and $A$ are the thickness, conductivity, and cross-sectional area of the disk. The conduction loss to the air is represented by a conduction shape factor, $S$, an effective air conductivity, $k_{a i r}$ and the 
temperature difference from the coupon to the enclosure. $V$ alues for $S$ and $k_{\text {air }}$ are never known independently; but values for their product are determined from Coupon 0 , the undusted polished aluminum coupon.

To obtain $S k_{\text {air }}$ from Coupon 0 , the known value of $\varepsilon=0.039$ is used in Eq. 3, and with that, Eq. 2 can be solved for $S k_{\text {air. }}$. That value is then applied to the coated coupons because the geometry and temperatures are the same, thus the same $S k_{\text {air }}$ product will apply to all. Any residual convective transfer is also accounted for with this method.

A decision was made early in the analysis to force the groupaveraged undusted values of $\varepsilon$ to agree with the values measured at NASA-Goddard. In doing so, the NASA Goddard values become the calibration standard for the experiment. The agreement was obtained by using a calibration factor, $C_{c a l}$, determined for each baseline run. The average $C_{c a l}$ for the experiments completed thus far is 0.968 .

\section{EXPERIMENTAL RESULTS}

Figure 9 is a plot of $\varepsilon$ for the Z-93P coating (coupons $1 \& 3$ ) for the clean baseline and four levels of dust. The clean baseline data from the two Z-93P coupons produced a two-sigma scatter of $\pm 8 \%$ and a mean deviation of $+2.3 \%$ from the NASA Goddard value of 0.93 . This is the largest baseline scatter of the three coatings. The NS-43G produced $\pm 3 \%$ scatter and a mean deviation of $+1.2 \%$, and the silver Teflon film produced a baseline scatter of $\pm 2.8 \%$ and a mean deviation of $-1.4 \%$. The small mean deviations are the result of the group-averaged calibration described in the Procedure section. The measured scatter at baseline conditions is the best estimate for the firstorder uncertainty of these measurements. However, if there is a significant deterministic change in $\varepsilon$ with coating temperature from 250 to $350 \mathrm{~K}$, that change contributes to the scatter quoted here. The dust loadings indicated on the abscissa are the average of the readings taken from the two microscope slides removed after each dusting. The two slides agree to within \pm $4 \%$ at best, and at worst, $\pm 14 \%$ for the highest loading.

As the weight of the dust deposition increased, $\varepsilon$ for the Z-93P coupons dropped from 0.93 to near 0.50 . This is to be expected: as dust obscures the coating, $\varepsilon$ should tend toward the emittance of the accumulated dust. For the maximum amount of dust in these tests, a plateau in $\varepsilon$ for Z-93P was not reached. We hypothesize that the substantial surface roughness of both the silicate paints, Z-93P and NS-43G, allows elements of the surface to project through the dust layer and raise the surface-averaged $\varepsilon$.

The role of the dusted, polished aluminum coupon (number 2) was to provide a measure of $\varepsilon$ for Carbondale Red Clay as no values were known to us prior to these experiments. Figure 10 shows that for this smooth, low- $\varepsilon$ surface, the first two levels of dust cause a dramatic increase in $\varepsilon$. A plateau is reached near 0.40 , and then $\varepsilon$ decreases at higher dust weights. As the dust thickens, the conductive resistance of the dust layer becomes significant, and the coupon temperature as measured at the main heater must be increased to provide a gradient through the dust layer. In essence, this causes the effective emittance, $\varepsilon$, to be lower than the true emittance of the dust surface itself. The process should be present to some degree in the high- $\varepsilon$ coupons, but it is masked by the large decrease in $\varepsilon$ as the true surface emittance tends downward. An adequate accounting of the resistance would require a conduction/radiation analysis of energy transport across the porous dust layer. Such an analysis has not been performed.

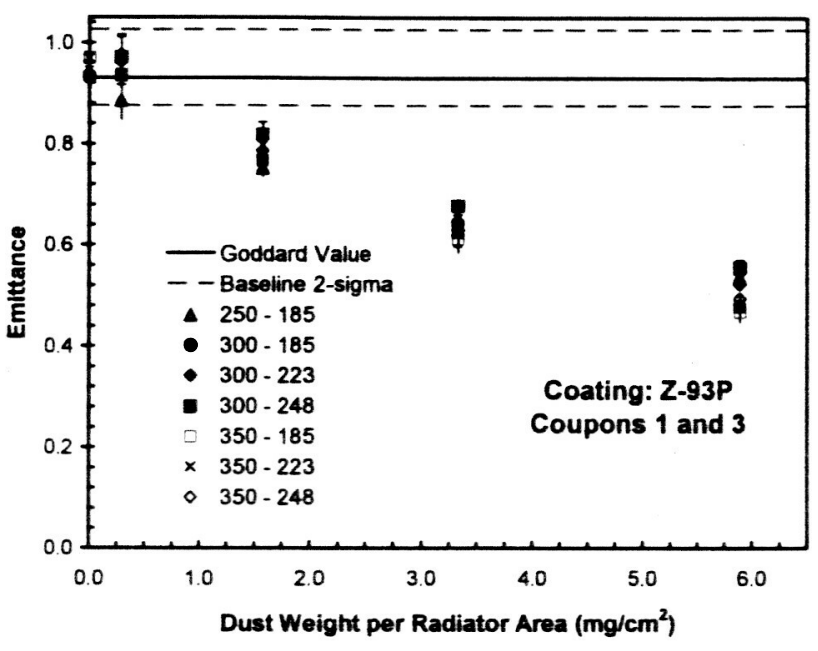

Figure 9. Results for Z-93P for a clean surface and four levels of dust. Each symbol represents the average $\varepsilon$ for coupons $1 \& 3$ at the $T_{\text {rad, }} T_{\text {sky }}$ pair shown in the legend.

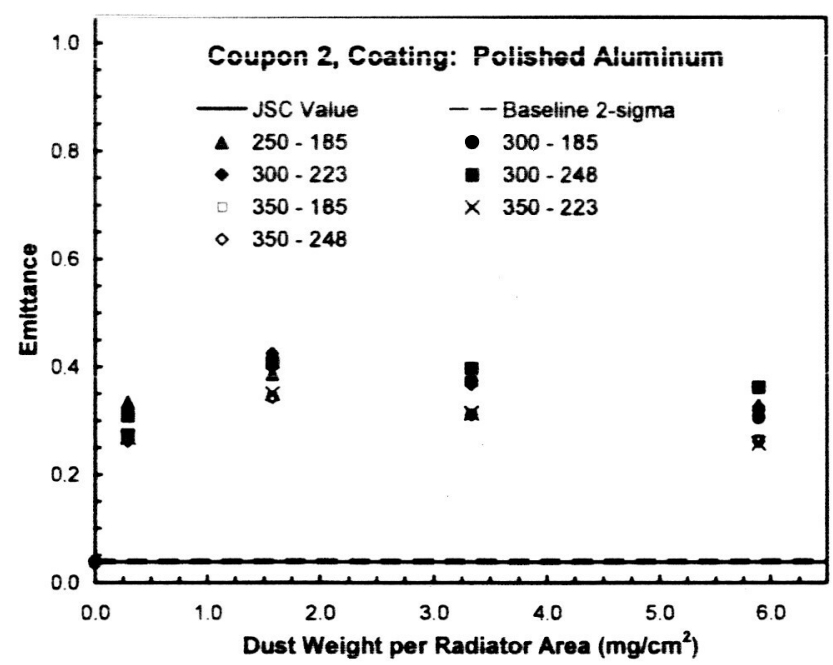

Figure 10. Results for polished aluminum for a clean surface and four levels of dust. Each symbol represents $\varepsilon$ for coupon 2 at the $T_{\text {rad, }} T_{\text {sky }}$ pair shown in the legend. 
Figure 11 is a composite plot showing results for all surfaces tested and for all combinations of surface and sky temperatures. The error bars show the two-sigma scatter at each dust level. The results for Z-93P and NS43G are virtually identical - both are rough surfaces with $\varepsilon$ near 0.92 . The silver Teflon film is affected more rapidly due to its smooth surface, and it approaches the best value indicated for the dust emittance $(0.4)$ from coupon 2. However, the silver Teflon displays a higher slope with dust loading than coupon 2 . As dust accumulates, $\varepsilon$ for all the surfaces should eventually display values near 0.4 and a linear reduction with dust weight. Thick dust layers should totally obscure the substrate, and the radiative properties of the dust surface along with the thickness of the layer should control the energy transport. At the levels of dust that were chosen for these experiments, that behavior is not evident in the high- $\varepsilon$ coatings, although the silver Teflon surface did approach this behavior at the highest dust loadings. To date, no directlyobserved thickness measurements have been made. However, the last two levels appear to obscure the original surface (see Figure 5).

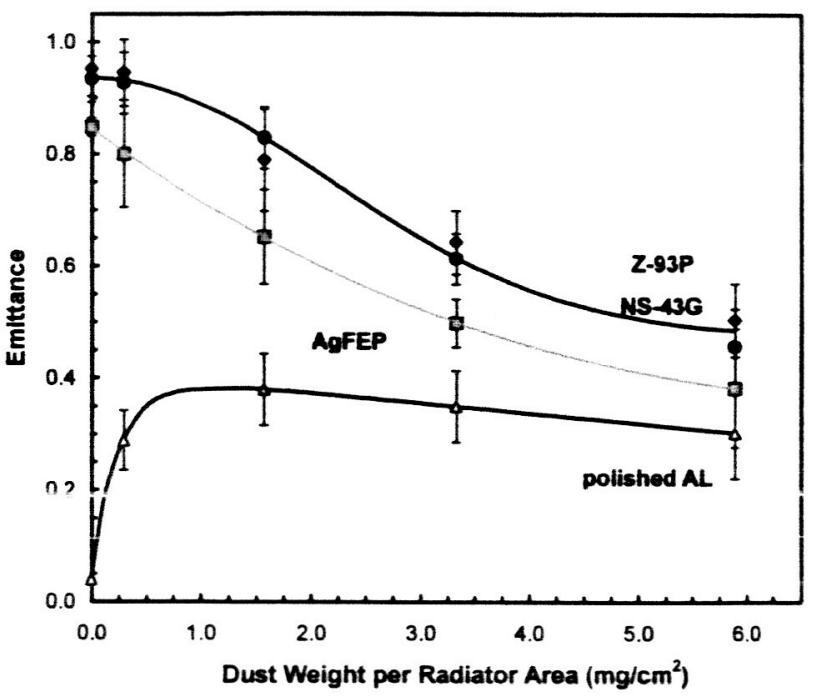

Figure 11. Composite plot of the effect of dust on all surfaces.

\section{SUMMARY}

A series of experiments to determine the effects of a Martian dust simulant (Carbondale Red Clay) on the effective emittance of candidate radiator coatings has been performed. The experiments required the development of a calorimetric apparatus that allows simultaneous measurements of the effective emittance for all the coatings at each set of experimental conditions. A method of adding dust to multiple radiator coupons was developed and shown to be capable of depositing dust on the surfaces with acceptable uniformity. One expects the detailed structure of the dust layer to be dependent on the details of the deposition process. In these experiments, the layer accumulates under earth gravity and in the presence of an earth atmosphere. Emittance measurements were then made at vacuum conditions.

The addition of dust causes the effective emittance of originally high-emittance surfaces to drop to near 0.5. A polished aluminum surface provided a measure of the emittance of the dust itself - approximately 0.4. As dust was added to the polished surface, the effective emittance went through a maximum and then declined slowly as the thermal resistance of the dust layer itself becomes significant. The reduction in emittance can be explained qualitatively in this way, but a quantitative prediction of the effect awaits an analysis that would include the combined effects of conduction and radiation within the porous layer.

\section{ACKNOWLEDGEMENTS}

This work was supported by NASA-JSC Grant NAG9-1421. Thanks are also due to Richard Snyder of NASA-JSC, who directed the testing facility, David Fletcher of the Advanced Design Office of NASA-JSC, who provided technical support during the design stage, and Eve Wooldridge of the Thermal Branch of the NASA Goddard Space Flight Center. We also greatly appreciate the efforts of Michael Reddington and Robert Fulmer of the NASA-JSC Energy Systems Test Area who maintained and operated the vacuum chamber during these experiments.

\section{REFERENCES}

1. Landis, G.A.: Dust Obscuration of Mars Solar Arrays. Acta Astronaut., vol. 38, no. 11, 1996, pp. 885-891.

2. Jenkins, P.P.; Landis, G.A.; and Oberle, L.G.: Materials Adherence Experiment--Technology. IECEC-97339, Proceedings of the 32nd Intersociety Energy Conversion Engineering Conference, Vol. 1, 1997, pp. 728-731.

3. Landis, G.A.: Mars Dust Removal Technology. IECEC97345, Proceedings of the 32nd Intersociety Energy Conversion Engineering Conference, Vol. 1, 1997, pp. 764-767.

4. Johnson, K. R., and Brinza, D. E, The Mars Thermal Environment and Radiator Characterization Experiment, Technical Paper 001CES-178, presented at the $30^{\text {th }}$ International Conference on Environmental Systems, Toulouse, FR, July, 2000. 
Appendix A: Images and graphs

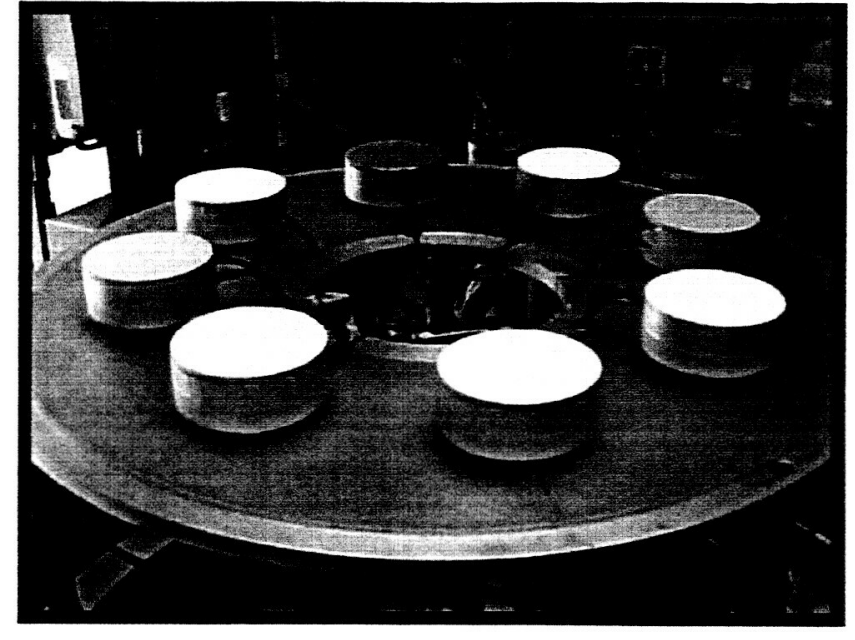

Initial coupon design without dust.

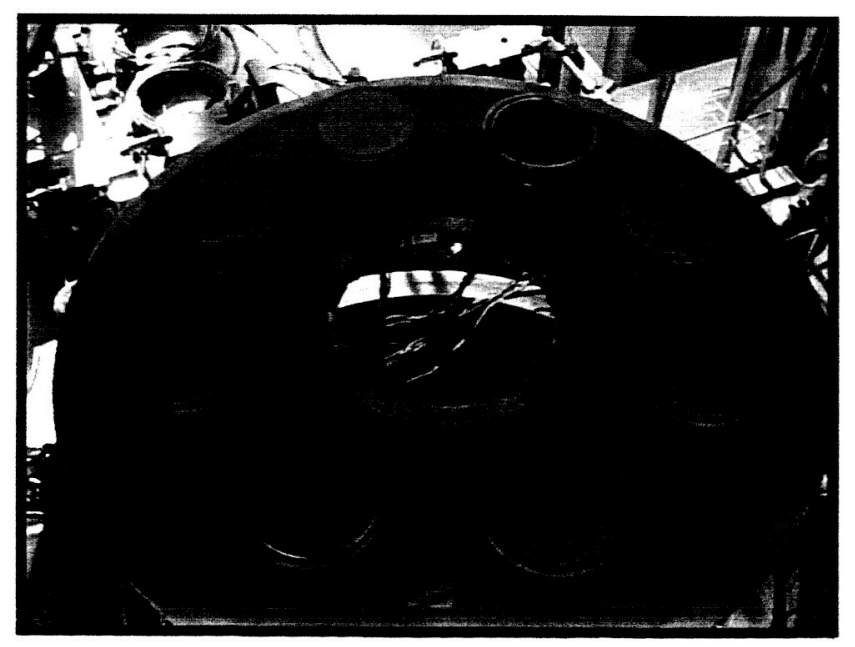

First dust level: $0.29 \mathrm{mg} / \mathrm{cm}^{2}$.

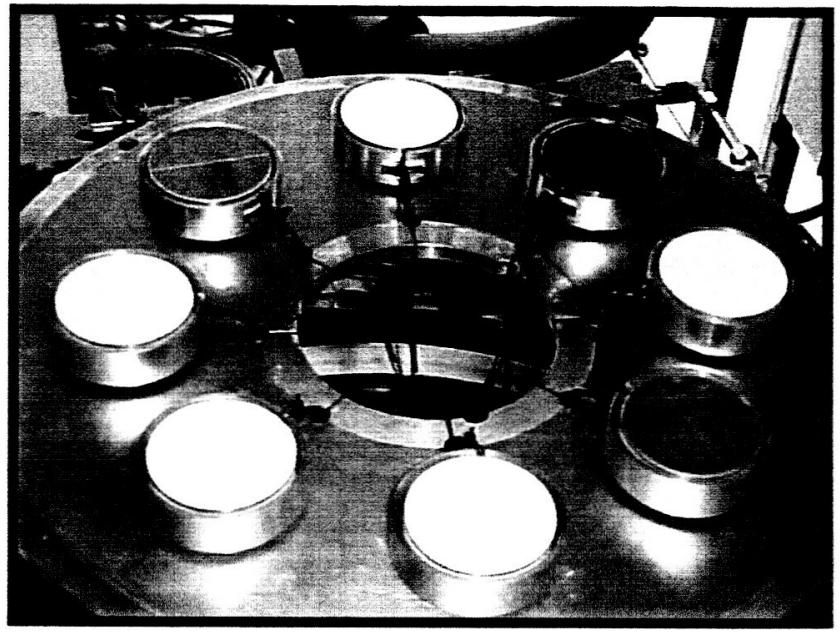

Final coupon design without dust.

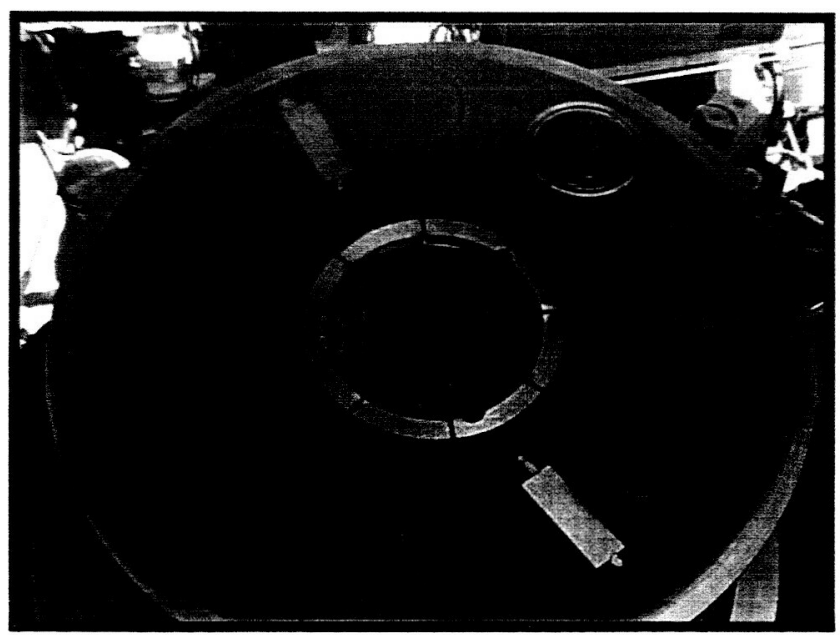

Second dust level: $1.57 \mathrm{mg} / \mathrm{cm}^{2}$. 


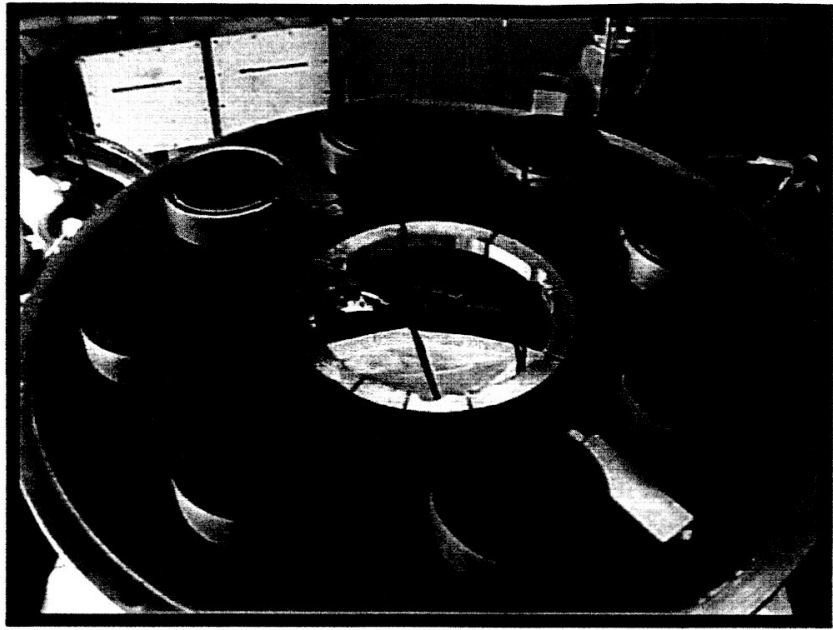

Third dust level: $3.33 \mathrm{mg} / \mathrm{cm}^{2}$.

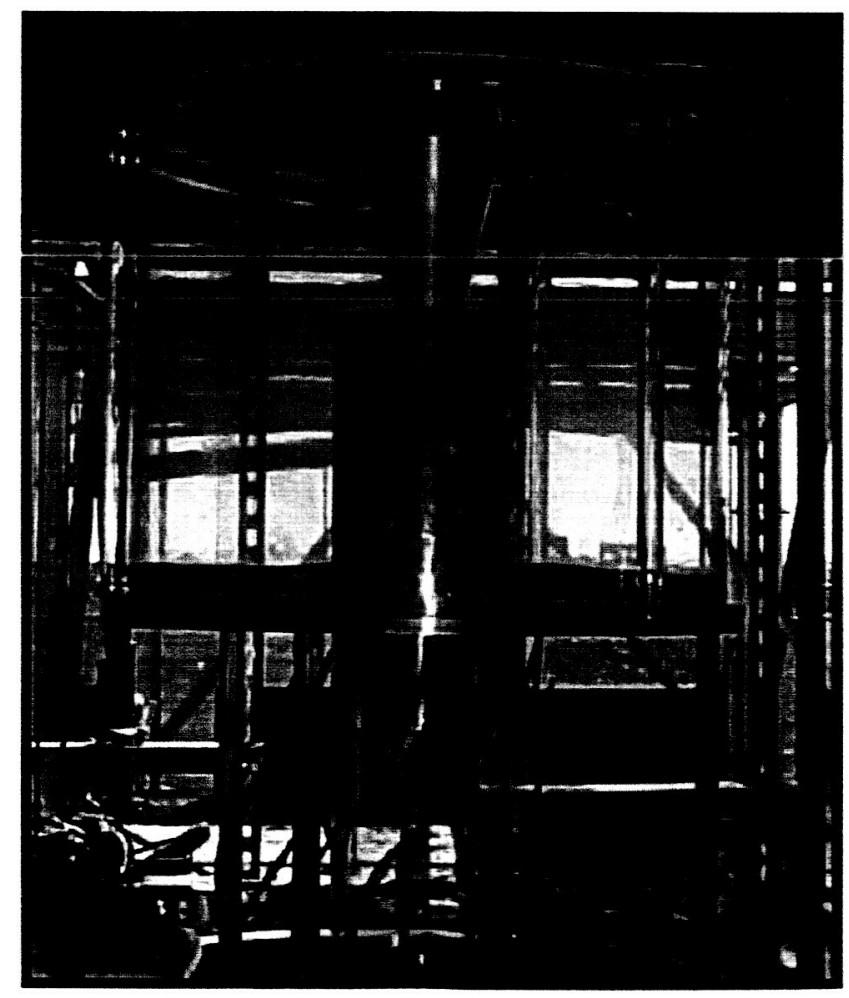

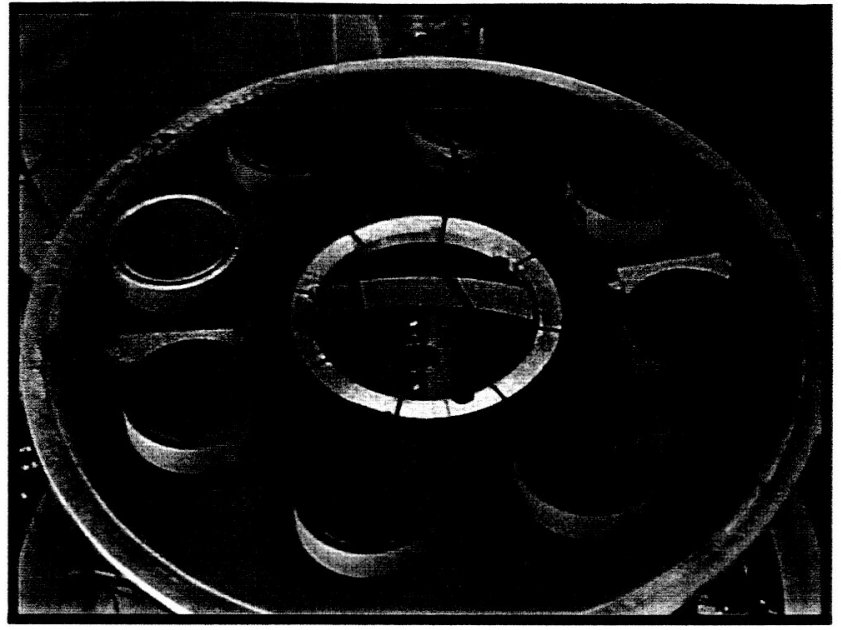

Fourth and final dust level: $5.9 \mathrm{mg} / \mathrm{cm}^{2}$.

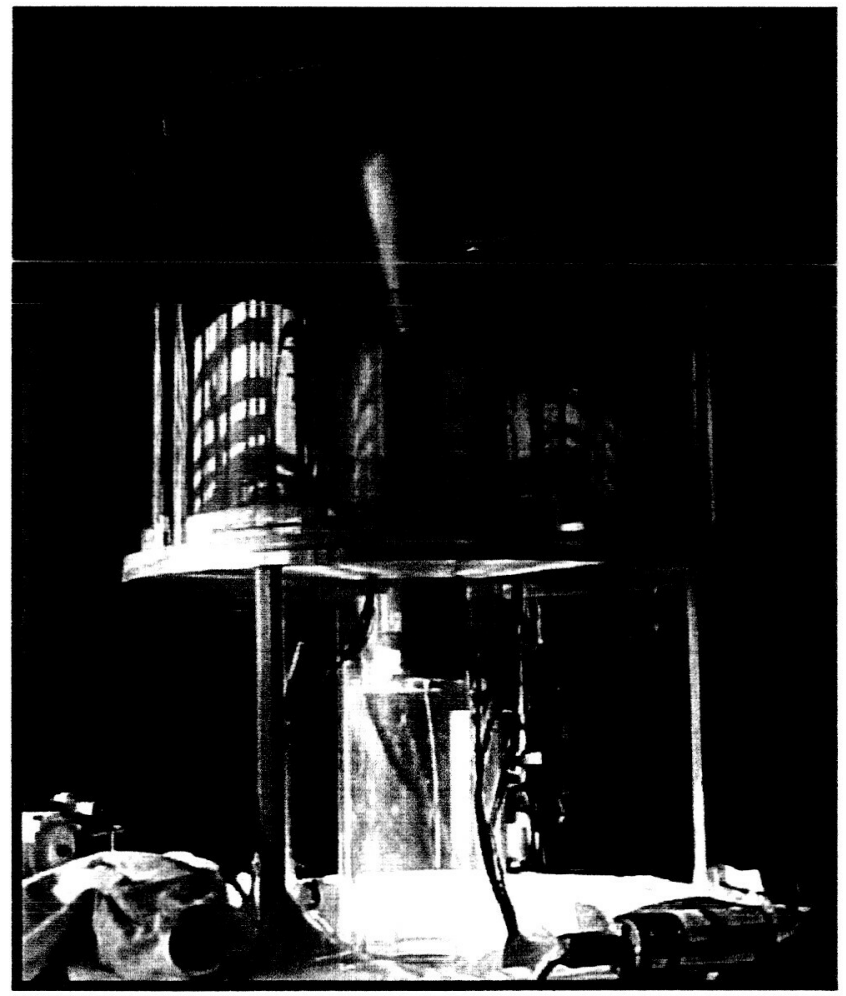

Dusting Apparatus: The central shaft and clear housing mount on the elevated floor of the vacuum chamber without disturbing the coupons. Filters at the base of the housing contain the dust while allowing the required air flow. Two glass slides are collected and stored after each dust deposition. 